\title{
MONARQUÍA Y PAISAJES PORTUARIOS EN LA EdAd Moderna: GÉNESIS DE LA ICONOGRAFÍA URBANA DE LAS CIUDADES ATLÁNTICAS DEL NORTE DE ESPAÑA
}

\author{
Carla Fernández Martínez \\ Universidad de Santiago de Compostela
}

Recibido: 29-11-2012 | Evaluado: 18-12-2013 | Aprobado: 18-12-2013

Resumen: A lo largo de la historia, el poder siempre se ha servido del arte como medio de propaganda y exaltación. De hecho, gran parte de las obras más relevantes de la Humanidad tuvieron finalidades políticas, representativas, ideológicas o propagandísticas. Partiendo de esta consideración, recorreremos el nacimiento de la iconografía urbana de las ciudades portuarias del norte de España, con el fin de entender su génesis en su contexto original. Se tratará de mostrar su vinculación con el afán de conocimiento propio de la Edad Moderna, pero también de ilustrar su uso práctico y simbólico por parte de la monarquía.

Palabras clave: iconografía urbana, ciudad portuaria, Arco Atlántico.

AвSTRACT: All through history, authorities have always used arts as a tool for propaganda and exaltation. In fact, many of the most important artworks of Humanity had political, representative, ideological or propagandistic aims. Starting from this consideration, we will revise the beginning of urban iconography of the port cities in the north of Spain, in order to understand its genesis within its original context. We will try to explain not only its link to the urge for knowledge, characteristic for the Modern Age, but also to illustrate its practical and symbolic usage by the Monarchy.

Keywords: urban iconography, port city, Atlantic Arc. 


\section{INTRODUCCIÓN}

A partir del Renacimiento el gusto por las vistas urbanas se difundió por el continente. Papas, nobles y soberanos comenzaron a encargar a numerosos artistas genuinos retratos de la ciudad y del territorio que cristalizaban su orgullo personal y, al mismo tiempo, materializaban la consistencia física e ideológica de la urbe. Desde entonces y hasta bien avanzada la Edad Moderna, la representación del paisaje urbano constituyó un medio eficaz de propaganda política, al tiempo que permitía conocer las peculiaridades de las poblaciones, el estado de sus fortificaciones y construcciones y las características geográficas de cada emplazamiento. En este contexto, nació la iconografía urbana de las ciudades portuarias y costeras del norte y noroeste peninsular. Fue entonces cuando el Arte y la Ciencia se dieron la mano para plasmar el aspecto de las poblaciones y su relación con la orografía del terreno. Se trató de una nueva actitud cognitiva, en la que participaron arquitectos, pintores, ingenieros, científicos y monarcas, ${ }^{1}$ que favoreció el perfeccionamiento de la pintura en Italia y de la cartografía en los Países Bajos, dando lugar a numerosas series de vistas, atlas geográficos y a las denominadas Camere delle Città o Gallerie delle Sale Geografiche, donde los mecenas se rodeaban de objetos variopintos alusivos al mundo urbano. ${ }^{2}$ La mayor parte de estas representaciones eran encargos regios y aristocráticos y tenían como prioridad exaltar sus dominios, así como conocer la geografía y las características de cada población. ${ }^{3}$ Por ello, a lo largo de la Edad Moderna, los monarcas se rodearon de astrónomos, geógrafos y pintores, al tiempo que se editaron obras tan destacadas como el Theatrum Orbis Terrarum de Abraham Ortelio, la Cosmografía de Sebastián Münster y Civitates Orbis Terrarum de Braun y Hogenberg.

En España, fue Felipe II el iniciador de esta campaña y fruto de su interés por la geografía y las vistas urbanas conservamos una magnífica colección de algunas ciudades españolas realizada por Anton Van den Wyngaerde. ${ }^{4}$ La serie, que satisfacía su deseo de poseer visualmente las principales urbes del reino, fue ideada como un estudio preparatorio para la decoración de los palacios reales. ${ }^{5}$ Wyngaerde incluyó extraordinarios retratos de algunos puertos, pero

1. Jean Marc Bese, Voir la terre, six essais sur le paysage et la géographie, Centre du paysage, Arles, 2000, p. 37.

2. Como ejemplos de aposentos con imágenes de ciudades destacan la Camera delle Città creada en 1490 por el segundo marqués de Mantua en la villa Gonzaga; poco después Baldassare Peruzzi pintó una serie de frescos con vistas de Roma en la villa Farnesina; ya en la década de los años setenta la familia Farnesio encargará la Sala delle Carte Geografiche para su palacio de Caprarola.

3. Sobre las relaciones entre la cartografía y la representación de la ciudad en época moderna existen diversas publicaciones, entre ellas: CESARE DE SETA, Le città dei cartografi. Studi e ricerche di storia urbana, Electa, Nápoles, 2008; Norman ThOwer, Mapas y civilización: historia de la cartografía en su contexto cultural y social, Ediciones del Serbal, Barcelona, 2002.

4. Las vistas de Van der Wyngaerde han sido estudiadas detenidamente por Kagan: RichARD KAGAN, Ciudades del siglo de oro. Las vistas urbanas de Anton Van der Wyngaerde, Visor, Madrid, 1986.

5. Sobre la función que atribuyó el monarca a la imagen, veáse: FERNANDo Bouza ÁlvarEz, Imagen y propaganda. Capítulos de historia cultural del reinado de Felipe II, Akal, Madrid, 1998. 
ninguno del norte; no obstante, unos años después, tres de ellos figuraron en una de las publicaciones más bellas del momento. Me refiero a las vistas de Santander, Bilbao y San Sebastián incluidas en Civitates Orbis Terrarum, obra de Franz Hogemberg y George Braun, editada en Colonia desde el 1572 hasta el $1618 .^{6}$

\section{Santander, Bilbao y San Sebastián en Civitates Orbis Terrarum}

Esta magna obra, compuesta por seis volúmenes, fue la más completa del momento. Probablemente, la idea de publicar una recopilación de vistas de ciudades surgió en torno a 1567 en Amberes. ${ }^{7}$ Contemporánea a la de Wyngaerde y al Teatrum Orbis Terrarum de Abraham Ortelio, como ellas pretendía dar a conocer el mundo o una parte del mismo.

En efecto, según Braun, la finalidad de Civitates era que el lector, sentado cómodamente en su butaca, aprendiese a través de las imágenes cosas acerca de otros pueblos y países, supliendo así lo que solo con largos, penosos y costosos viajes podría descubrir. ${ }^{8}$ George Braun era un clérigo de Colonia dedicado al conocimiento de la ciudad terrenal, y Frans Hogenberg un grabador de Malinas que se encargó del trabajo técnico. Desde 1572 y hasta 1617 se publicaron los seis volúmenes integrados por más de quinientas ciudades, en su mayor parte de Europa. Para la realización de esta magna obra, primero localizaron corresponsales en todo el mundo a los que solicitaron vistas y textos sobre la historia, las costumbres, la economía, etc. de cada núcleo poblacional. En el caso español, contaron con la ayuda de George Hoefnagel, un dibujante excelente que realizó los bocetos entre 1563 y 1567; un siglo después, en 1657, Johannes Janssonius compró las planchas para publicarlas en un solo volumen: Theatrum Hispaniae Urbes. ${ }^{9}$

Para representarlas no siguieron un mismo criterio compositivo $y$, aunque parten de un punto de vista elevado e imaginario, en algunos casos nos encontramos con vistas a vuelo de pájaro y en otros, con panorámicas, tipología a la que se adscriben la mayor parte de las urbes hispanas. ${ }^{10} \mathrm{La}$ ciudad se muestra en un segundo plano, pero dominando el territorio y el paisaje circundante; de su morfología destacan aquellos edificios más significativos, mientras que el caserío aparece de manera homogénea. Además, cada lámina

6. Luis SAzATornil Ruiz, «Entre la vela y el vapor. La imagen artística de las ciudades portuarias cantábricas», en La ciudad portuaria atlántica en la historia: siglos XVI-XIX, Servicio de Publicaciones de la Universidad de Cantabria, Santander, 2006, pp. 87-11.

7. Abraham Ortelius, Theatro del Mondo de Abraamo Ortelio. Venecia, 1667.

8. Sobre las intenciones de la obra existe un interesante artículo de Santiago Paéz, véase: ElENA Santiago PAÉz, Teatro de las más ilustres ciudades de España y Portugal, Lunwerg, Barcelona, 1996.

9. Idem.

10. Sobre la clasificación tipológica de las vistas urbanas, véase: CESARE DE SETA, «La classificazione tipologica dell'iconografia urbana», en L'Europa moderna. Cartografia urbana e vedutismo, Electa, Nápoles, 2002, pp. 28-32. 
se acompañaba de motivos alusivos a la vida cotidiana, a sus ciudadanos, indumentarias y costumbres. ${ }^{11}$

Entre las diecinueve ciudades españolas se encontraban las vistas de Bilbao [Fig. 1], San Sebastián [Fig. 2] y Santander [Fig. 3]. Su inclusión se relaciona con la importancia que estaban comenzando a adquirir y significaba, como ha apuntado Sazatornil Ruiz, «pasar de ser oscuras villas costeras a convertirse simbólicamente en miembros del selecto grupo de las ciudades más importantes de todo el Orbe». ${ }^{12}$

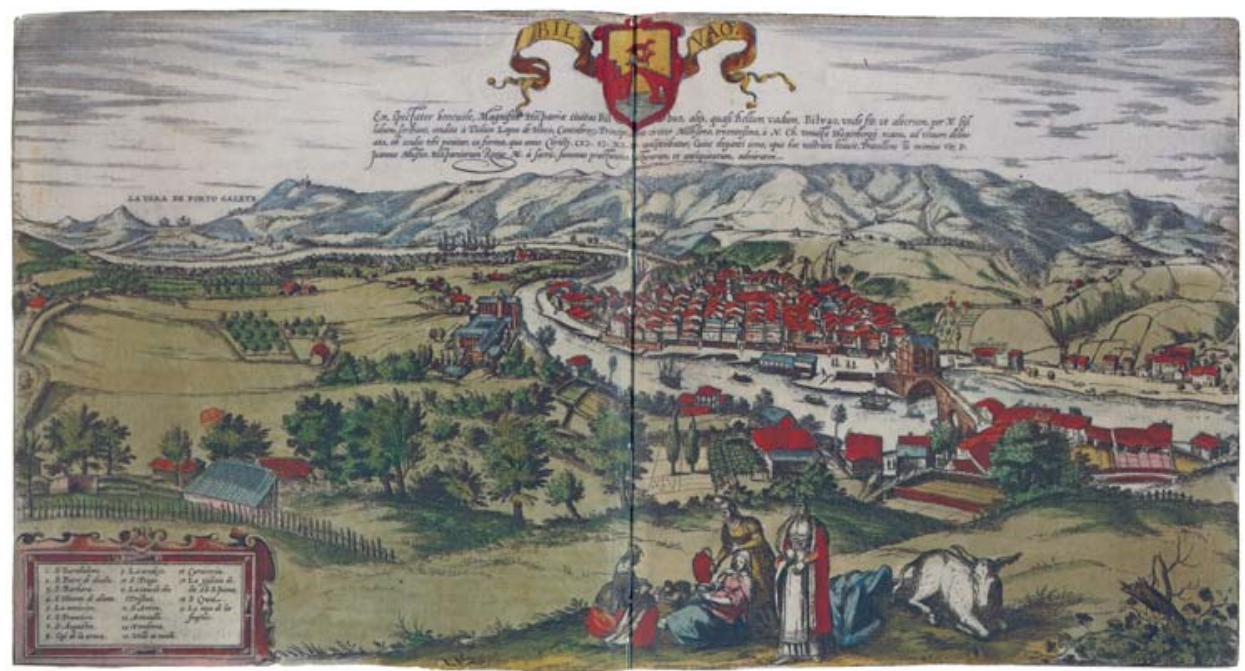

Fig. 1. Bilbao. Civitates Orbis Terrarum. Hogemberg-Braun, 1572. (http://historic-cities.huji.ac.il/mapmakers/braun_hogenberg.html. 03-03-2012)

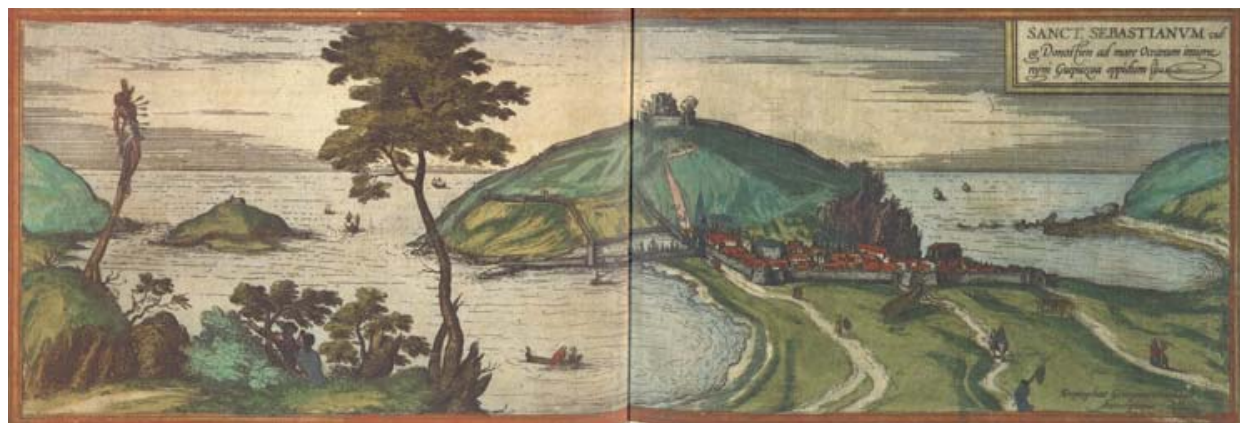

Fig. 2. Sanct Sebastianvm. Civitates Orbis Terrarum, Diputación de Valladolid

11. Para profundizar en la evolución de las vistas de Santander, véase: Luis Sazatornil Ruiz, Begoña Alonso Ruiz Y ANa Martín Huescar, Vistas y visiones. Imagen artística de Santander y su puerto, 15751950, Navalia, Santander, 1995. Sobre Bilbao: Miguel Zugaza Miranda, La Ría: Imagen y visión de un paisaje mercantil, Museo de Bellas Artes de Bilbao, Bilbao, 1993 (cat. exp.). OleAGA, «Estampas de Bilbao», en Bilbao. Estampas 1575-1860, Bilbao, Museo Vasco, Bilbao, 2000, pp. 19-22.

12. Luis SazATORNil Ruiz, «Entre la vela y el vapor. La imagen artística de las ciudades portuarias», p. 90. 


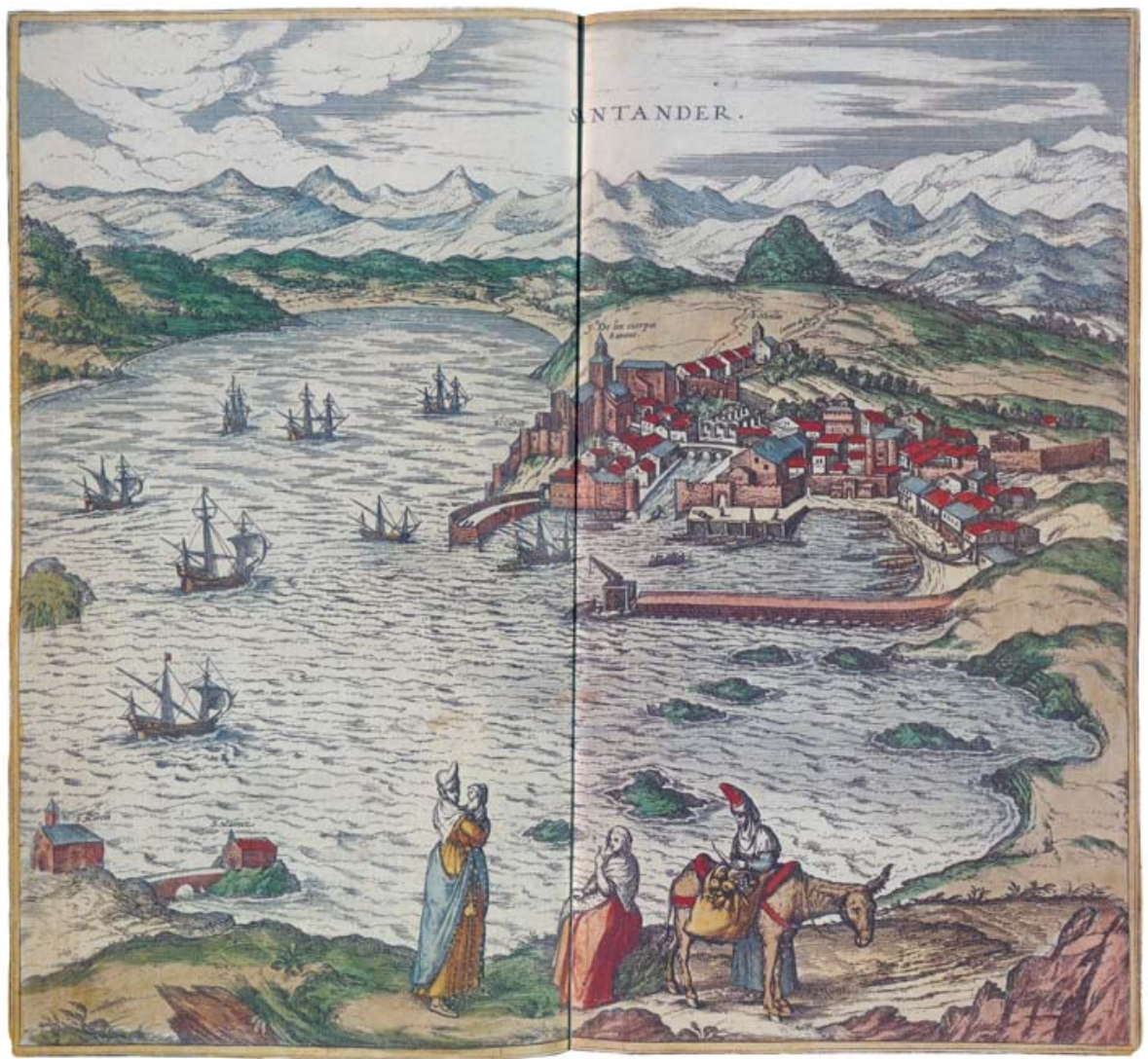

Fig. 3. Santander. Civitates Orbis Terrarum, Museo Marítimo del Cantábrico

Ciertamente, fueron los únicos ejemplos del litoral cantábrico que tuvieron el privilegio de figurar entre los más relevantes del mundo. Sin embargo, si analizamos detenidamente la selección de ciudades, advertimos que su representación puede estar también relacionada con la intención de plasmar en la obra los diferentes modelos geográficos urbanos.

Partiendo de las peculiaridades citadas, en Santander sobresalen los conventos de San Francisco y Santa Clara y la muralla. A la izquierda se sitúa la parte antigua con la abadía y el castillo y a la derecha la Puebla Nueva, ambas unidas por el puente de sillería. Es llamativo el protagonismo concedido al puerto, donde distinguimos las modestas casas de los marineros. En comparación con ella, la vista de San Sebastián posee un formato más apaisado para incidir en sus características geográficas. Aparece como una ciudad abierta al mar, de ahí que se destaque la complejidad y la interacción que se produce entre la villa y el océano. Por último, en la representación de Bilbao forzaron la perspectiva al objeto de abarcar desde el convento de la Encarnación, en la carretera de Bermeo, hasta la desembocadura de la ría en Portugalete. 
En cualquier caso, estas imágenes inauguraron la iconografía portuaria cantábrica. La serie gozó de un gran éxito y en las centurias sucesivas se reeditó y tradujo a un gran número de idiomas. ${ }^{13}$ Sus láminas se convirtieron en imágenes tópicas, promoviendo una visión estática de la ciudad y del puerto que sirvió de motivo e inspiración hasta bien entrado el siglo XIX. ${ }^{14}$

\section{LA DESCRIPCIÓN DE ESPAÑA Y LAS COSTAS Y PUERTOS DE SUS REINOS}

Unas décadas después, en 1634, apareció una colección encargada por la monarquía y que incluyó un buen número de imágenes alusivas a las ciudades y villas de la franja atlántica, especialmente de sus plazas fuertes. Se trata de la Descripción de España y de las costas y puertos de sus reinos, comisionada por Felipe IV y ejecutada por el cosmógrafo portugués Pedro Texeira ${ }^{15} \mathrm{La}$ obra ha sido rigurosamente estudiada por Marías y Pereda, así que partiremos de sus consideraciones. ${ }^{16}$

Felipe IV había accedido al trono en 1621, en un momento delicado políticamente -guerra con los Países Bajos, hostilidad con Francia...-, que requería medidas para la salvaguardia de las costas peninsulares; de ahí que pronto comprendiese la necesidad de tener un mayor conocimiento del litoral español, motivo que le llevó a promover y acometer la mayor obra cartográfica del siglo XVII. ${ }^{17}$

Tras la muerte del cosmógrafo Jao Baptista Lavanha, Pedro Texeira fue el único responsable de la empresa. Inicialmente, se había planteado la posibilidad de documentar todo el territorio peninsular, pero se consideró que era prioritario conocer las características de la costa y sus plazas fuertes. Texeira debía presentar un corpus iconográfico que permitiese apreciar de forma precisa la posición de cada puerto para facilitar la navegación y calcular su distancia con respecto a las fortificaciones, faros, monumentos más destacados y accidentes geográficos. Su ejecución en solitario implicó nueve

13. Entre las copias de Civitates destana las de: Francesco VAllegio, Raccolata di le più illustri citti di tutto il mondo, Venecia, 1572; Pieter VAn Der Aa, Galerie agreable du monde, 1701; JuAn Álvarez De Colmenar, Les delices de L'Espagne E du Portugal, 1707.

14. Luis Sazatornil Ruiz, Begoña Alonso Ruiz Y Ana Martín Huescar, Vistas y visiones...

15. Se había considerado que esta obra había desaparecido, pero se encuentra depositada en la Hofbibliothek de Viena (Codez Miniatus 46). Texeira realizó también un plano de Madrid bajo el título de Topographia de la Villa de Madrid; otros dibujos de las poblaciones vascas y el Compedium Geographicum dedicado al primer marqués de Leganés que contiene un mapa del Orbe, otro de España y seis más de la costa cantábrica y de Galicia. Para mayor información véase: Compendivm Geographicvm, Madrid, 2001.

16. Fernando Marías Y Felipe Pereda (coord.), El Atlas del Rey Planeta, Nerea, Hondarribia, 2002. Fernando Marías Y Felipe Pereda, «De la cartografía a lo corografía: Pedro Texeira en la España del Seiscientos», en Ería, 64-65, Oviedo, 2004, pp. 129-157.

17. Para mayor información sobre el uso de la imagen por Felipe IV, véase: JonATHAN Brown Y JOHN Elliot, Un palacio para el rey. El Buen Retiro y la corte de Felipe IV, Taurus, Madrid, 2003. RICHARD KAGAN, «Imágenes y política en la corte de Felipe IV», en La historia imaginada, Centro de Estudios la Europa Hispánica, Madrid, 2008. pp. 101-119. 
años de trabajo de campo y otros tres en el taller, pero aseguró un criterio de descripción homogéneo. ${ }^{18}$

El resultado fue la creación de un atlas detallado, integrado por ricas descripciones y tres tipos de documentos gráficos: los dibujos de las poblaciones del litoral, los mapas de las diversas regiones que facilitan su localización y, por último, uno de la península y otro del orbe; esto es, aparecían recogidos dibujos topográficos, corográficos y geográficos. ${ }^{19}$ Texeira recorrió las costas desde Fuenterrabía hasta Rosas, también parte de la portuguesa, tomando notas de los puertos vizcaínos, guipuzcoanos, montañeses, asturianos y gallegos [Fig. 4].

Lo que nos interesa son sus dibujos topográficos; no se trata de vistas panorámicas, puesto que están tomados desde un punto imaginario y elevado, más si cabe que en los de Braun, como si nos situásemos por encima del mar. Esta perspectiva le permitió recrearse en la plasmación de las peculiaridades geográficas y estratégicas, mientras que la traza urbana está solo esbozada, sobresaliendo algunos de los edificios más emblemáticos. Por otro lado, concedió un gran protagonismo al mar, deteniéndose en su plasmación y ofreciendo información sobre el oleaje y las corrientes [Fig. 5].

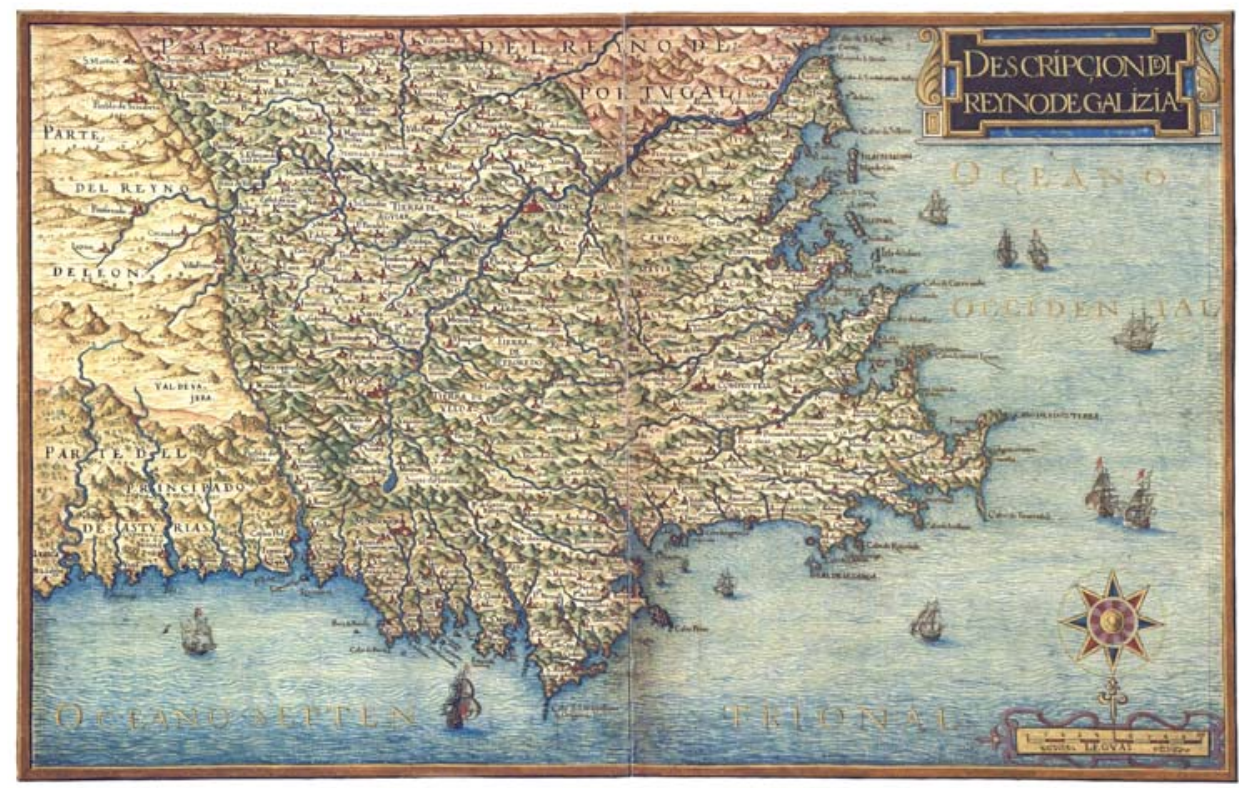

Fig. 4. Descripcion del Reyno de Galicia. La Descripción de España y de las costas y puertos de sus reinos. Pedro Texeira, 1634, Hofbibliothek de Viena

18. DANiEl MARíAs, «La llave del atlas: génesis, ejecución y contenido de un relato geográfico sobre el litoral de la Península», en El Atlas del Rey Planeta. pp. 67-95.

19. Agustín Hernando, «Poder, cartografía y política de siglo en la España del siglo xviı», en El Atlas del Rey Planeta... pp. 71-95. 


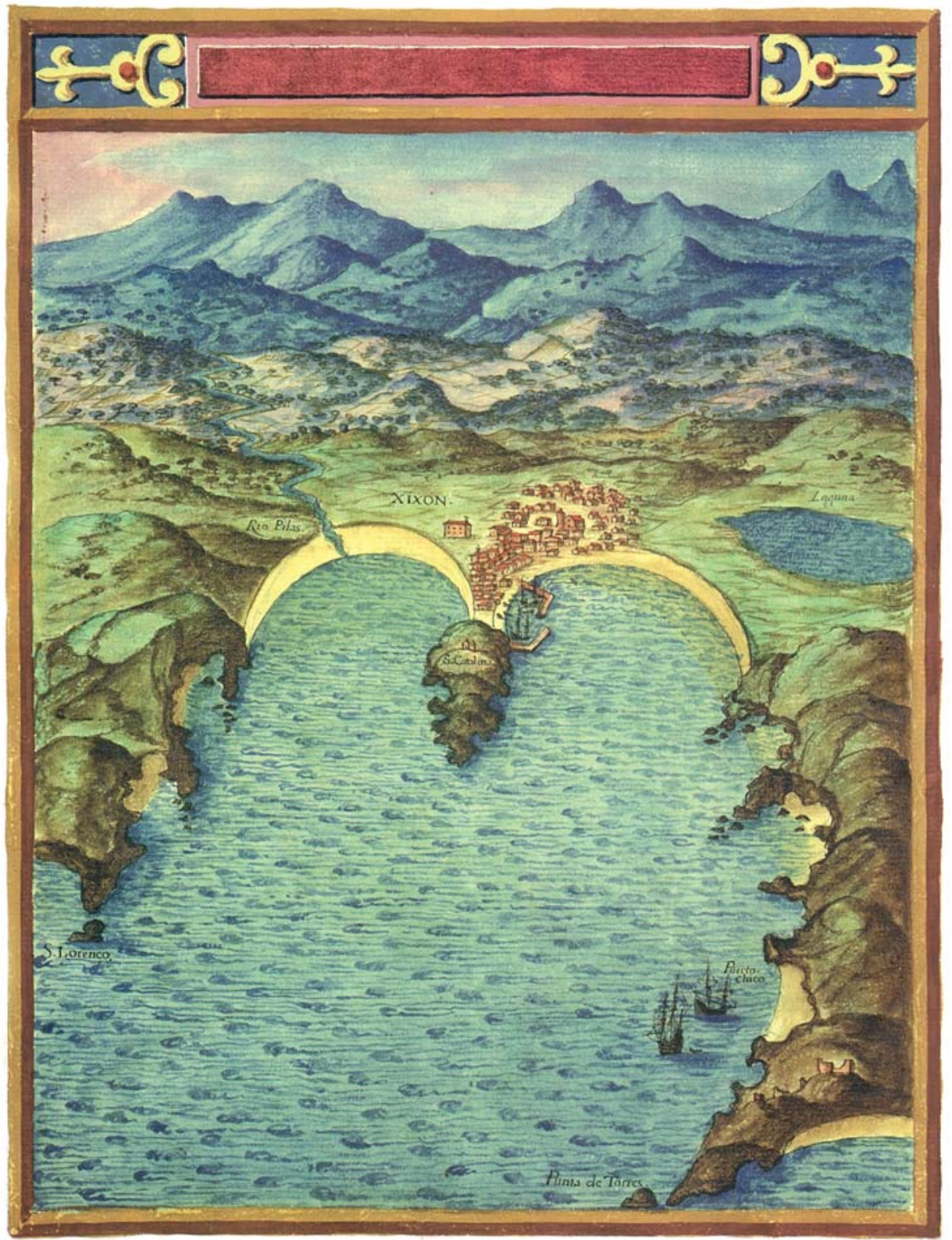

Figura 5. Xixon. La Descripción de España y de las costas y puertos de sus reinos. Pedro Texeira, 1634, Hofbibliothek de Viena

La relevancia de la obra se debe a que, además de ser una de las más originales de esta época, muestra la trascendencia política que tenía el conocimiento del territorio costero. Felipe IV fue perfectamente consciente de ello y supo instrumentalizar el Arte y la Ciencia para entender la importancia estratégica de las villas y ciudades norteñas [Fig. 6]. 


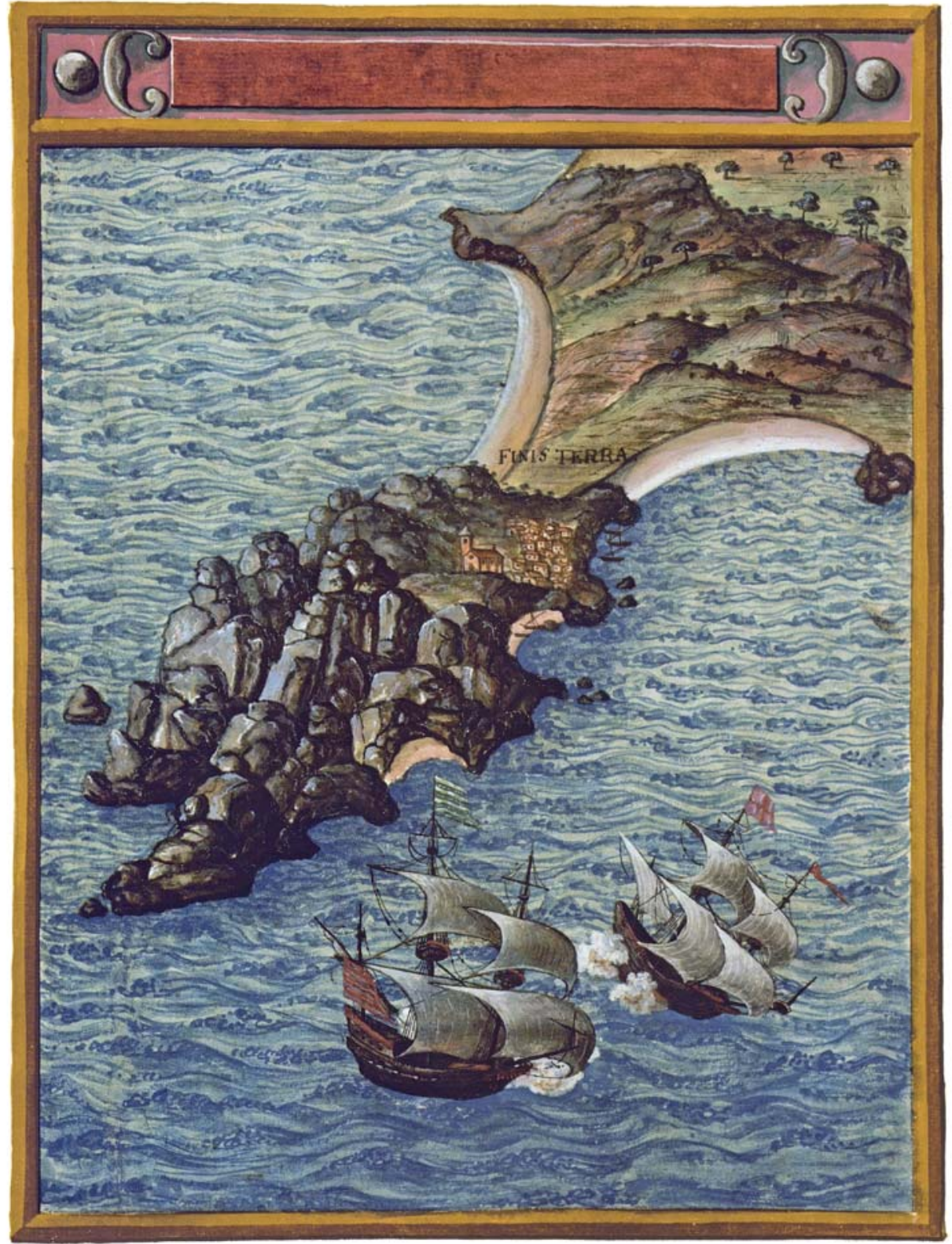

Fig. 6. Finisterra. La Descripción de España y de las costas y puertos de sus reinos. Pedro Texeira, 1634, Hofbibliothek de Viena

Las vistas de Luis Paret y Mariano SÁnChez: De LA IDEALIZACión a LA EXALTACIÓN DEL PROGRESO

El reinado de Carlos II, con sus intrigas y complicaciones, fue la puntilla que remató un siglo en el que España estuvo inmersa en una profunda crisis. Sin 
embargo, en el siglo XVIII se sucedieron una serie de reformas que permitieron atajar la situación, renovándose la agricultura, la industria y el comercio. Solo las consecuencias de la guerra de la Independencia y las vicisitudes políticas y sociales del siglo XIX interrumpieron las ansias de progreso de los Borbones. ${ }^{20}$

En este contexto, aparecieron dos de las series más significativas sobre nuestras ciudades portuarias y costeras. Me refiero a las vistas realizadas por Luis Paret y Alcázar, a petición de Carlos III a partir del 1786, y las de Mariano Sánchez, encargadas por Carlos IV en $1792 .{ }^{21}$ El gusto por las vistas de puertos se había difundido en Europa, tras una producción francesa patrocinada por Luis XV y realizada por Claude-Joseph Vernet. ${ }^{22}$ Los lienzos gozaron de un gran éxito y se divulgaron en grabados por todo el continente. Posiblemente, despertaron el deseo de nuestros monarcas de poseer una colección de características semejantes, pudiendo servir de inspiración a Paret ${ }^{23}$ y a Sánchez.

Luis Paret y Alcázar había estudiado en la Academia de Bellas Artes de San Fernando y en Roma, pensionado por el infante don Luis, con el que mantenía una estrecha relación. ${ }^{24}$ Tras un incidente en la casa de su mecenas, fue desterrado a Puerto Rico. ${ }^{25}$ En 1778 se le conmutó la pena y se instaló en Bilbao, ciudad en la que se casó y vio nacer a sus dos hijas. Una vez allí, comenzó a interesarse por el tema marino y en 1783 pintó una vista del Arenal de Luchana y otra de Bermeo. El 4 de julio de 1786 recibió el encargo de Carlos III de realizar las vistas de los puertos, con la obligación de entregar dos obras al año. ${ }^{26}$ Se desconoce el número exacto de los lienzos, aunque se limitó a los vascos. ${ }^{27}$ El monarca quería contemplar y exponer en la Casita del Príncipe de El Escorial los puertos y marinas de su reino, por lo que Paret los dotó de un efecto decorativo, acorde con su propio estilo. ${ }^{28}$ De este modo, los concibió como paisajes compuestos con figuras en primer plano que centran la composición y justifican el fondo [Figs. 7 y 8]. Presentan escenas costumbristas con pescadores, estibadores, mujeres trabajando, caballeros, damiselas, clérigos, frailes y soldados en un ambiente tranquilo y relajado, donde el realismo remite a

20. Jesusa VegA, Ciencia, arte e ilusión en la España Ilustrada, CSIC, Madrid, 2010.

21. Mariano Sánchez comenzó a trabajar para Carlos III en 1781, momento en el que recibió el encargo de realizar una colección completa de todas las vistas de puertos y bahías de España e islas adyacentes, así como de sus arsenales; no obstante, fue ya bajo el mandato de Carlos IV cuando ejecutó las relativas a Galicia, Asturias y Santander.

22. Florence Ingersoll-Smouse, Joseph Vernet: peintre de marine, 1714-1789, Bignou, París, 1926.

23. Véase: Luis Sazatornil Ruiz, «Entre la vela y el vapor», op. cit. p. 101. En el inventario de Paret, con motivo de su viaje a Madrid en 1787 figuraban algunas de las láminas.

24. Para mayor información sobre el pintor, véase: Osirir Delgado, Luis Paret y Alcázar. 1957.

25. AA. vv., Luis Paret y Alcázar, Servicio de publicaciones del Gobierno Vasco, Vitora, 1991. pp. 59-78.

26. El 4 de julio de 1786, Carlos III comisionó a Paret para pintar las vistas de los puertos cántabros. Debía entregar, al menos, dos obras al año con una remuneración anual de 15.000 reales. Véase: AA. VV., Luis Paret y Alcázar. pp. 92-95.

27. La Vista del Arenal de Bilbao (colección particular), datada en 1783, fue posiblemente su primera obra, aunque no perteneció a la serie, al igual que las de Bermeo y la del Astillero de Olaveaga. Al encargo regio corresponden las de La concha de San Sebastián, La vista de Fuenterrabía y el Puerto de Pasajes.

28. Juan Antonio Gaya Nuño, «Luis Paret y Alcázar», en Boletín de la Sociedad Española de Excursiones, 1952. 


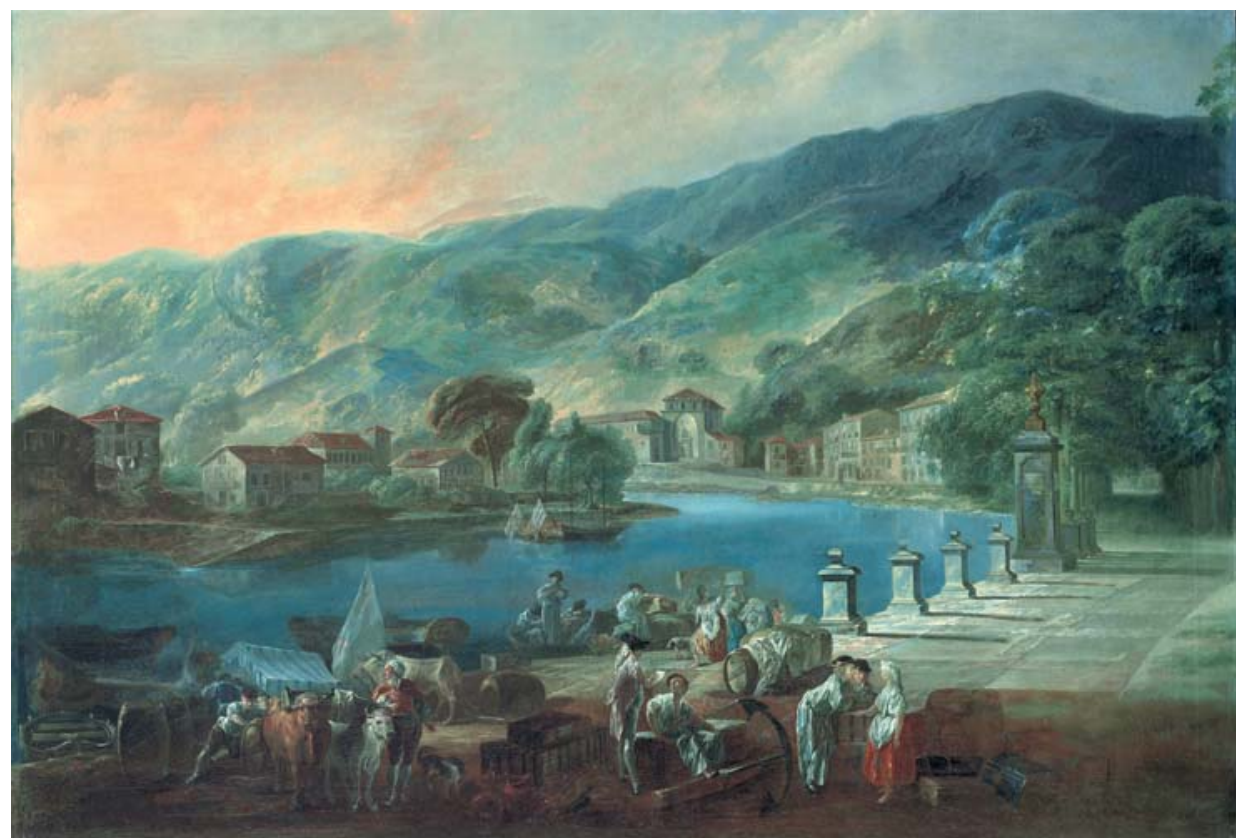

Fig. 7. Vista del Arenal de Bilbao, 1783, Museo de Bellas Artes de Bilbao

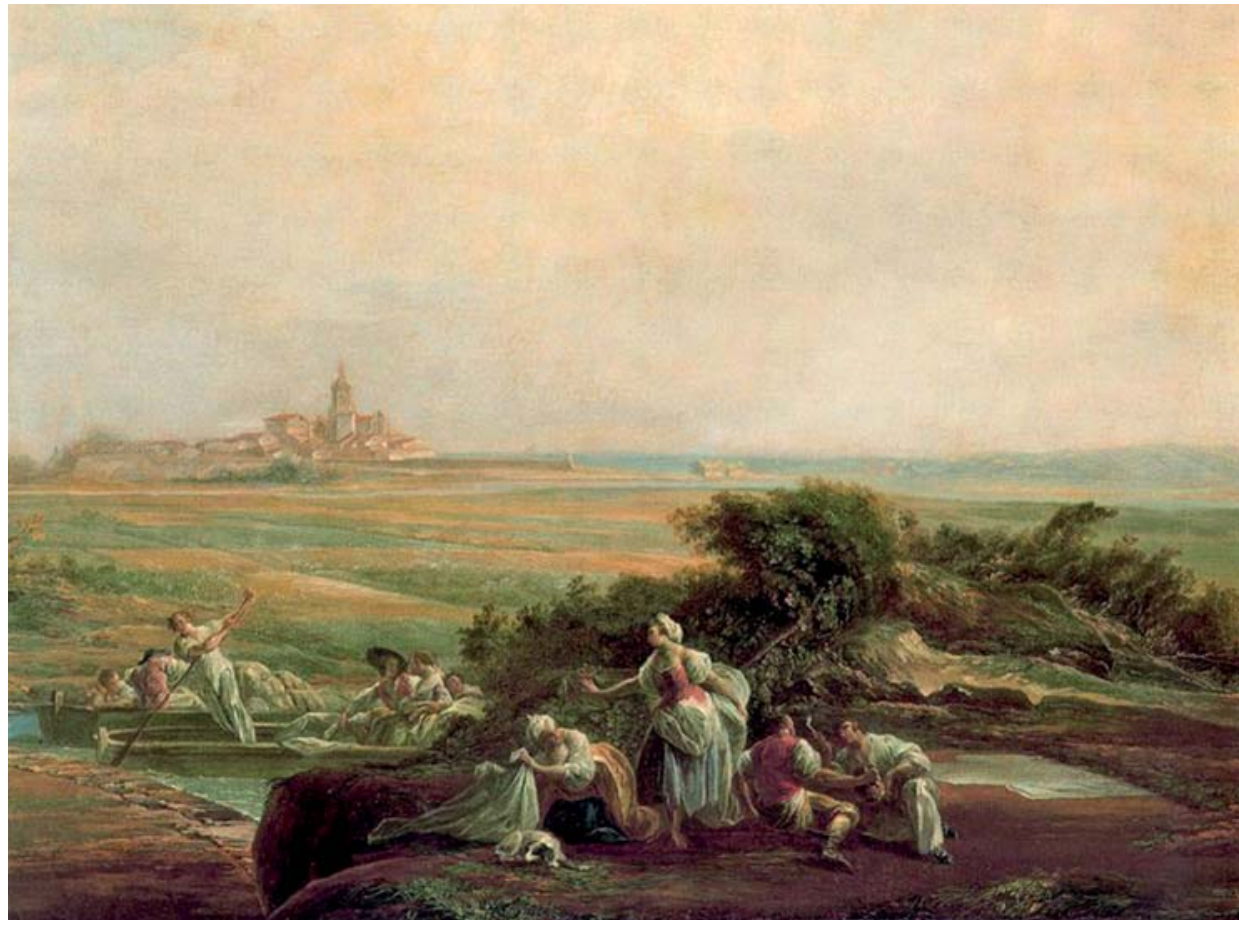

Fig. 8. Vista de Fuenterrabía. LuIS PARET y AlCÁzar, 1786, Museo de Bellas Arte de Bilbao 
favor de una imagen placentera y sosegada, similar a la que Vernet dejó de los puertos francos.

En esos mismos años, Mariano Sánchez comenzó a cultivar también esta temática. ${ }^{29} \mathrm{Al}$ igual que Paret, se había formado en la Academia de San Fernando ${ }^{30}$ y pronto destacó por sus cualidades de miniaturista, trabajando al servicio del rey de Portugal. ${ }^{31}$ Fue en 1781 cuando el futuro Carlos IV le encargó una colección completa de todas las vistas, puertos y bahías de España e islas adyacentes y de sus arsenales. ${ }^{32}$ Aunque el objetivo era dejar constancia de los logros producidos por las reformas, también respondían al afán descriptivo y de conocimiento propio de la Ilustración. ${ }^{33}$ Por otro lado, estaban destinadas a decorar diversas estancias del Palacio Real de Madrid y de la Casita del Príncipe en El Escorial. ${ }^{34}$ La obra se inició en 1781; el artista se trasladó a Cádiz para comenzar las vistas de Andalucía, pasando por el norte en $1792 .{ }^{35}$ Ese año emprendió su periplo por Galicia, Asturias y Santander, tomando notas de aquellos enclaves más significativos. Desde Coruña recorrió el litoral gallego, después se dirigió a Asturias y finalmente llegó a Cantabria. Si comparamos su obra con la de su predecesor [Figs. 9 y 10], comprobamos que la diferencia fundamental es que abandonó esa imagen idealizada y placentera, para mostrar la pujante situación de las ciudades y villas del litoral, favorecidas por las iniciativas regias. El carácter preciso de sus lienzos y las notas que hemos conservado ratifican la utilización de la cámara oscura. Este artilugio se conocía desde el siglo XVI, pero se puso especialmente de moda en esta centuria. Con él los pintores podían acercarse con exactitud a la naturaleza y obtener pautas fiables para su plasmación. Así, Sánchez, tras obtener los

29. Las referencias bibliográficas sobre el pintor se encuentran recogidas en diversos estudios, aunque cabe destacar: Marcos Antonio De Orellana, Biografía pictórica valentina. Editorial Xavier de Salas, Valencia, 1967, pp. 441 y ss.

30. Enrique Pardo Canalís, Los registros de Matrícula de la Academia de San Fernando de 1752 a 1815, Real Academia de San Fernando, Madrid, 1967, pp. 104.

31. Adela Espinós Díaz, «Mariano Sánchez (1840-1822): Paisajista al servicio de la Corte», en El Arte en tiempos de Carlos III, Alpuerta, Madrid, p. 324.

32. El conjunto de lienzos ha sido estudiado por: Esther Alba PAgán, «La pintura y los pintores valencianos en las "casitas" del Real Sitio de San Lorenzo del Escorial: Mariano Salvador Maella, Benito Espinós, Miguel Parra, José López Enguídanos y Mariano Sánchez», en El Monasterio del Escorial y la pintura: Actas del Simposium, San Lorenzo de El Escorial, 2001, pp. 759-784. MARía LuiSA BARRENO Sevillano, «Vistas de puertos. Cuadros de Marino Sánchez pintor al servicio de Carlos IV», en Reales Sitios, 51, 1977, pp. 37-44. Adela Espinós Díaz, «Mariano Sánchez»; José De La Mano, «Mariano Sánchez y las colecciones de vistas de puertos en la España de finales del siglo viII», en I Congreso Internacional de Pintura Española del siglo XVIII, Marbella, 1998, pp. 351-369. José Luis Morales Marín, Pintura en España 1750-1808, Cátedra, Madrid, 1994. pp. 245-246. JUAN José JUNQUERA MATO, La decoración y el mobiliario de los palacios de Carlos IV, Organización Sala Editorial, Madrid, 1979. Luis Sazatornil Ruiz, «Entre la vela y el vapor», pp. 102-103. Por su parte, ha sido reproducidos en: España y el mar en el siglo de Carlos III. Madrid, 1989; y en Gijón, puerto ilustrado, Gijón, 2003 (cat. exp.).

33. En este sentido, es pertinente señalar que paralelamente a esta serie se encomendó al pintor Luis Meléndez otra sobre los productos del territorio español.

34. Actualmente, la mayor parte de ellos pertenece a Patrimonio Nacional, al Museo del Prado y a la Academia de San Fernando.

35. La documentación relativa a este trabajo se encuentra en el expediente personal del pintor en el archivo del Palacio Real. Caja 961/47. 


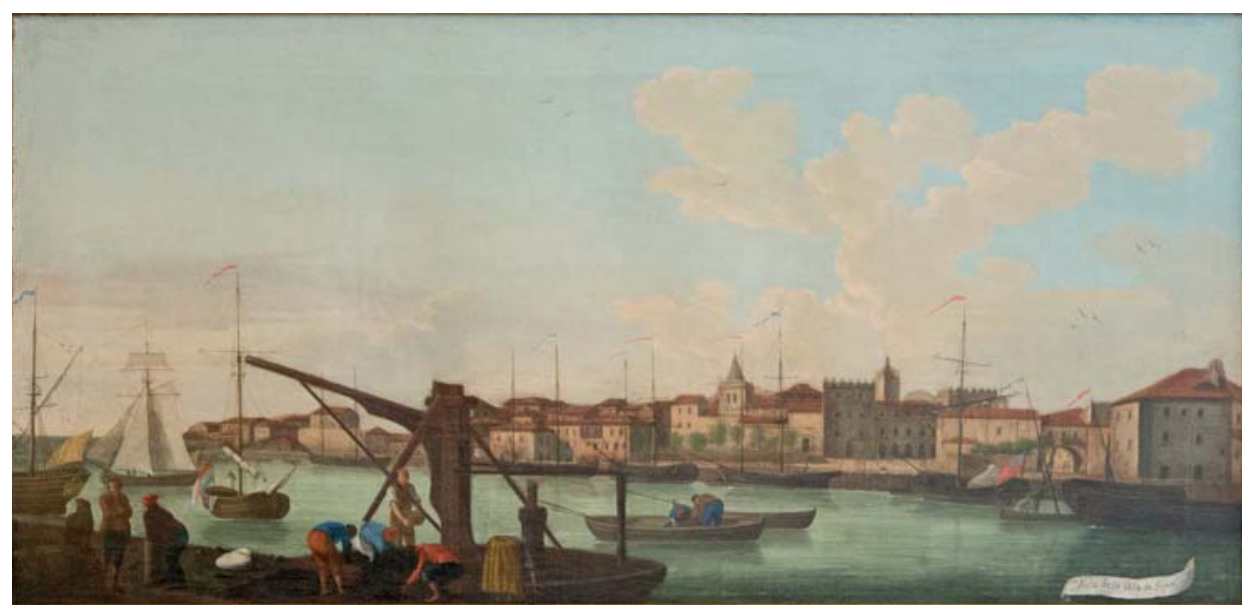

Fig. 9. Vista de la villa de Gijón. Mariano Ramón SÁnCHez, 1793, Palacio Real. Patrimonio Nacional

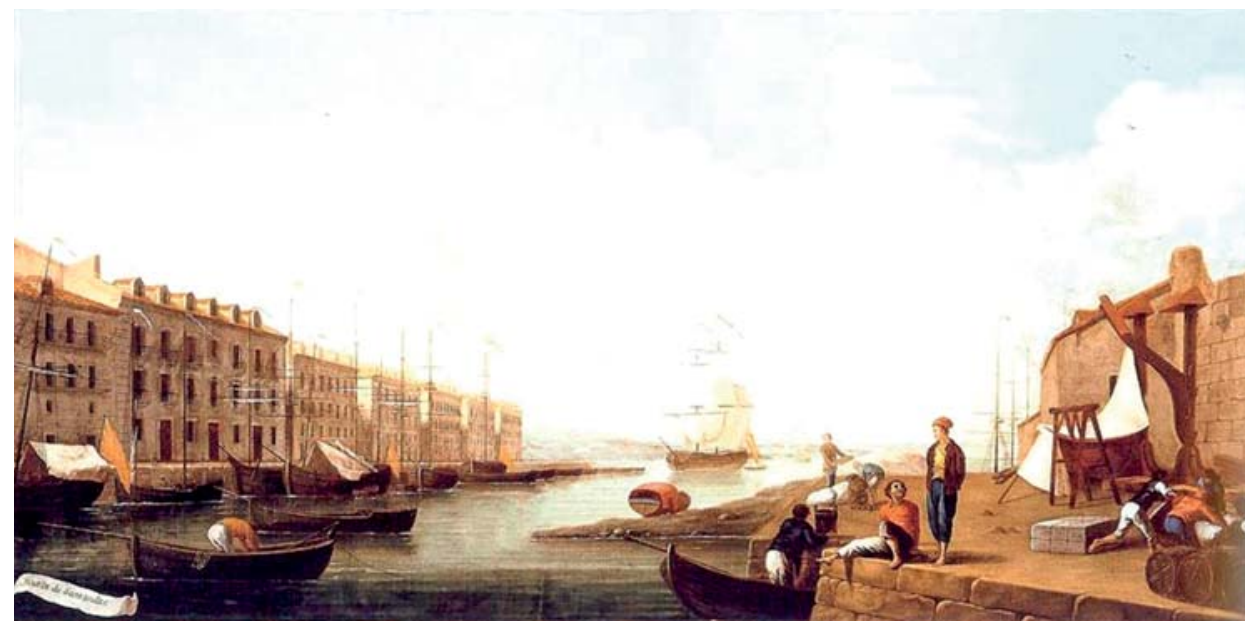

Fig. 10. Muelle de Santander. Mariano Ramón Sánchez, 1793, Palacio Real. Patrimonio Nacional

bocetos, concluía en Madrid sus lienzos, añadiendo los elementos secundarios, como barcos, figuras y referencias meteorológicas. Es este el motivo por el que, en palabras de González Santos, su estilo es muy lineal y responde a la obligación de calcar las imágenes proyectadas. ${ }^{36}$ Además, ese horizonte bajo, las pequeñas figuras de espaldas y los contrastes lumínicos, reflejan una clara influencia y conocimiento de la pintura de los Países Bajos.

36. Javier GonzÁlez Santos, «La vista de San Lorenzo y del Campo Valdés de Gijón: un cuadro del paisajista Mariano Ramón Sánchez pintado para Jovellanos», en Archivo Español de Arte, 308, 2004, pp. 385-395. En este artículo su autor, además de analizar la vista de puertos de Mariano Sánchez, se centra en el comentario de dos lienzos sobre Gijón, realizados por el pintor para Jovellanos. 
No fueron estas las únicas series sobre los puertos españoles; también se realizaron otras con una intención divulgadora entre un público más amplio. Alexander Jean Noel recorrió la península junto con el grabador François Allix para elaborar varios grabados de tema marítimo; el proyecto no pudo concluirse y solo se efecturon dos entregas con vistas de Lisboa, Cádiz y Cartagena. Por otro lado, Pedro Grolliez fue el responsable de unos dibujos como base para otra serie de grabados. De los originales tan solo se conocen los relativos a la vista de la ría de Vigo, Bayona, Avilés, Ribadeo y Ferrol, ${ }^{37}$ pero la obra se componía de treinta. ${ }^{38}$ Los grabados se encomendaron a Tomás López Enguídanos y no fueron del agrado de Grolliez. Por ello, se le autorizó para que los realizara en solitario, aunque solo se publicaron los del puerto de Cádiz, Sevilla y Luarca. A diferencia del precedente francés, ${ }^{39}$ Grolliez se detuvo en la descripción topográfica más que en la plasmación de los puertos, centrándose en unos cielos poblados de nubes. Como ya había hecho Vernet, colocó en primer término a personajes del lugar y otros individuos ataviados con mayor elegancia, en alusión a él y alguno de sus acompañantes. El objetivo era dar a conocer los puertos en torno a los que giraba el nuevo desarrollo económico.

Lo interesante de estas colecciones es que constatan cómo las vistas de nuestros puertos fueron utilizadas por la monarquía para expresar su poderío y grandeza. Ciertamente, aunque la iconografía urbana norteña nació vinculada al anhelo por conocer el mundo, los soberanos pronto comprendieron que la representación de sus dominios, al igual que la de sus victorias, era una forma de exaltar su figura y transmitirla al futuro. En realidad, el paisaje portuario entendido como el resultado de la interpretación personal del artista, no apareció hasta bien entrado el siglo XIX, coincidiendo con el apogeo del género en España.

\section{NOTA FINAL}

A lo largo de este artículo se ha tratado de exponer brevemente los usos y funciones que motivaron el nacimiento de la iconografía urbana de la ciudad portuaria norteña en la Edad Moderna. Se ha pretendido resaltar su importancia como documento histórico y cultural de un periodo en el que el arte se puso al servicio del poder. Precisamente, fue en esta época cuando la imagen inundó la esfera de la comunicación política y se convirtió en un eficaz medio para

37. Para mayor información véase: AA. vv.: Catálogo general de la Calcografía Nacional, Calcografía Nacional, Madrid, 1987. José CARRETE, «La real Calcografía de Madrid en la época de Goya», en La Real Calcografía de Madrid. Goya y sus contemporáneos, Ministerio de Asuntos Exteriores, Madrid, 1984, pp. 42-43.

38. El autor declaraba que: «enemigo de la ociosidad, espero con ansia nuevas órdenes, sea para seguir el mismo trabajo en el interior del Reyno, sea por cualquier otra comisión». Ahn. Consejos, II. 277/32.

39. Las cinco acuarelas se custodian en la Colección Rodríguez Moñino- Buy. Véase: YARA SonSECA, Dibujos de la colección Rodríguez Moñino-Brey, Fundación Cultural Mapfre, Madrid, 2002, pp. 196-200. 
transmitir ideas, aspiraciones e ideales de gobierno. ${ }^{40} \mathrm{Y}$ es que, aunque la mayor parte de los estudios sobre el uso de la imagen como propaganda se han centrado, sobre todo, en la Rusia soviética, la Alemania nazi o la Italia fascista, en todas las épocas la pintura fue utilizada por los gobernantes para generar en el pueblo los sentimientos adecuados e inmortalizar sus figuras. ${ }^{41}$

De la misma forma que el retrato y la estatua sirvieron para idealizar sus personalidades, las vistas de sus dominios constituyeron una forma de expresar su poderío. Ciertamente, es ese el contexto que explica el protagonismo adquirido por las ciudades portuarias del norte; unas ciudades que en su condición de ser lugares de idas y venidas, de guerras y exploraciones eran parte de uno de los imperios marítimos más extensos y duraderos que han existido. Sus vistas se presentaban, así, como una forma de perpetuarlo y conservar su memoria en el futuro, haciendo visible lo que ya no está.

40. Al respecto puede ser de gran interés: JOAn Lluís PAlos, CARRIó-Invernezzi, Diana, La historia imaginada. Construcciones visuales del pasado en la Edad Moderna, Centro de Estudios Hispánicos, Madrid, 2008. Alicia Cámara Muñoz, José García Melero y Antonio Urquízar Herrera, Arte y poder en la Edad Moderna, Editorial Universitaria Ramón Areces, Madrid, 2010.

41. Peter Burke, Visto y no visto: el uso de la imagen como documento histórico, Crítica, Barcelona, 2001, p. 76. 